\title{
Multiple Arterial Conduits for Multi-Vessel Coronary Artery Bypass Graft in Patients with Mild to Moderate Left Ventricular Systolic Dysfunction: A Multicenter Retrospective Study
}

\author{
Hang Zhang \\ Nanjing First Hospital \\ Wen Chen \\ Nanjing First Hospital \\ Yang Zhao \\ Nanjing Medical University \\ Lichun Guan \\ Shanghai Eighth People's Hospital \\ Min Yu \\ Shanghai General Hospital \\ Rui Wang ( $\nabla$ wr1582@163.com ) \\ Nanjing First Hospital

\section{Xin Chen} \\ Nanjing First Hospital
}

Research article

Keywords: Radial artery; Internal thoracic artery; Coronary artery bypass graft; Left ventricular systolic dysfunction

Posted Date: July 30th, 2020

DOI: https://doi.org/10.21203/rs.3.rs-49935/v1

License: (c) (1) This work is licensed under a Creative Commons Attribution 4.0 International License. Read Full License 


\section{Abstract}

Background: Advantages of multiple arterial conduits for coronary artery bypass graft (CABG) have been reported previously. We aimed to evaluate the mid-term outcomes of multiple arterial CABG (MABG) among patients with mild to moderate left ventricular systolic dysfunction (LVSD).

Methods: This multicenter study using propensity score matching (PSM) took place from January 2013 to June 2019 in Jiangsu Province and Shanghai, China, with a mean and maximum follow-up of 3.3 and 6.8 years, respectively. We included patients with LVSD, underwent primary, isolated multi-vessel CABG with left internal thoracic artery (LITA). The in-hospital and mid-term outcomes of MABG versus traditional LITA supplemented by saphenous vein grafts [single arterial CABG (SABG)] were compared. The primary endpoints were death from all causes and death from cardiovascular causes. The secondary endpoints were stroke, myocardial infarction (MI) and repeat revascularization, and a composite of all mentioned outcomes, including death from all causes [major adverse events (MAEs)]. Sternal wound infection was included with 6 months of follow-up after surgery.

Results: 243 and 676 patients were formed in the MABG and SABG after PSM in a 1:3 ratio. Compared with SABG, MABG was associated with lower rate of MAEs (HR, 0.64; 95\% Cl, 0.44-0.94; $\mathrm{P}=0.02)$, MI (HR, $0.39 ; 95 \% \mathrm{Cl}, 0.16-0.99 ; \mathrm{P}=0.05)$ and repeat revascularization (HR, $0.42 ; 95 \% \mathrm{Cl}, 0.18-0.97 ; \mathrm{P}=0.03)$. There was no difference in the rate of death, stroke, and sternal wound infection.

Conclusions: In patients with mild to moderate LVSD, MABG was associated with reduced mid-term rate of MAEs and cardiovascular events, but without reduced rate of death and stroke. MABG did not increase sternal wound infection rate.

\section{Introduction}

Left ventricular systolic dysfunction (LVSD) is associated with poor clinical outcomes in patients suffering from coronary artery disease [1], and surgical treatment is effective and provides survival benefit. Several non-randomized studies and the Surgical Treatment for Ischemic Heart Failure (STICH) randomized trial had consistently shown improved survival and lower rate of cardiovascular causes, among patients with impaired left ventricular (LV) function who underwent coronary artery bypass graft (CABG) [2-5]. Nevertheless, the choice of grafts and optimal grafting strategy in patients with LVSD remained elusive, since these individuals were in the status of long-lasting hypoperfusion and ventricular remodeling, and it required a long time for LV functional recovery after surgical revascularization [6].

Up to now, no randomized, controlled trials but several large observational studies demonstrated of a lower mortality and fewer cardiovascular events in patients received multiple arterial CABG (MABG) compared with who received single arterial CABG (SABG) [7-9]. Theoretically, the better prognosis of MABG may be probably related to superior patency of arterial conduits in the general CABG population. However, when extended to patients with LVSD, it would be argued whether impaired LV function could be recovered from this superiority. A few investigations on long-term survival of MABG in comparison with 
SABG in patients with LVSD came to a different conclusion [10-12]. In addition, none of studies did describe the specific cause of death which in many cases maybe due to noncardiac factors and thus unrelated to graft durability and choice. Herein, we conducted a multicenter propensity score matching (PSM) study cohort to evaluate the mid-term outcomes of MABG among patients with mild to moderate LVSD.

\section{Patients And Methods}

\section{Patients}

All patients received primary isolated CABG from the 11 institutions in Jiangsu Province and Shanghai, China, from January 2013 to June 2019, were identified through the Jiangsu Province CABG Registry (221.226.218.114:10004/Multicenter) and Chinese Cardiac Surgery Registry (CCSR)-CABG section (ccsr.cvs-china.com). The two databases are linked through the user's identifier ID, with similar parameter codes. All data were deidentified before being delivered for analysis and no additional patient informed consent specific to this study was required given its retrospective nature. This study was approved by the ethics committee of Nanjing First Hospital (KY20170811-03).

\section{Study Design}

Patients were excluded if they met following criteria: (1) concomitant procedures or prior cardiac surgery; (2) single vessel disease; (3) did not receive left internal thoracic artery (LITA); (4) with preoperative left ventricular ejection fraction (LVEF) $\geq 53 \%$ or $<30 \%$; (5) hemodynamic instability that needed an intraaortic balloon pump (IABP) or left ventricular assist device support before surgery; (6) urgent or emergency surgery was also excluded, as these individuals were more likely to receive venous conduits. All eligible patients were with mild to moderate LVSD, multi-vessel coronary artery disease undergoing primary, isolated CABG and received at least LITA. Patients who received a LITA with either a radial artery (RA-MABG) or right internal thoracic artery (RITA-MABG), or both comprised the MABG group; patients who received a LITA supplemented by saphenous vein grafts (SVG) comprised the SABG group.

\section{Arterial Grafting Strategy Of Mabg}

The choice and combination of grafts were based on coronary artery anatomy, severity of coronary artery stenosis, and size of the grafted vessel. Internal thoracic artery grafts were predominately harvested with a pedicle. All the LITA were in-situ and used as single distal anastomosis directed to left anterior descending artery (LAD) in $94.3 \%$, and to other arteries in $6.7 \%$. For RA grafts, $71.5 \%$ were anastomosed to a single distal artery, $18.7 \%$ were used as sequential anastomoses, and $9.8 \%$ were performed as $\mathrm{Y}$ - or Tgrafts. The RA was used in most patients $(67.2 \%)$ to bypass the left circumflex (LCX) region with target vessel stenosis of at least $70 \%$, followed by right coronary artery (RCA) territory (8.5\%). $71.2 \%$ of RITA were in-suit and used to bypass the RCA and LAD territories in approximately $34 \%$ of patients. In addition, 
$28.8 \%$ of RITA were available used as free grafts to mostly bypass the LCX and LAD territories. $33.6 \%$ of patients received total arterial grafts and $66.4 \%$ of patients received MABG supplemented by SVG.

\section{Outcomes}

The primary endpoints were death from all causes and death from cardiovascular causes. The secondary endpoints were: (1) major adverse events (MAEs) which defined as the composite of death from all causes, stroke, myocardial infarction (MI) or repeat revascularization; (2) the individual components of the MAEs including stroke, $\mathrm{Ml}$, and repeat revascularization, reported as time-to-event outcomes; and (3) sternal wound infection with 6 months of follow-up since surgical procedure. The safety outcomes included in-hospital events: postoperative death and complications. Patients were censored on January 31,2020 , and those who lost to follow-up were included in the analysis according to the last data record in the registries.

All CABG were performed by experienced surgeons in each institute. The surgical procedures and standard intensive care unit (ICU) protocols were approximately similar in each institute, including cardiopulmonary bypass, ventilator support, sedation, and pain management. For postoperative variables, prolonged mechanical ventilation was defined as mechanical ventilation or reintubation for more than 24 consecutive hours after operation [13]. Prolonged ICU stay was defined as a threshold of 48 hours after transferring to ICU [14]. Death from cardiovascular causes included death caused by sudden cardiac death, $\mathrm{Ml}$, or heart failure. Stroke was defined as an incident ischemic or hemorrhagic cerebral event. MI included any subsequent visit for treatment of an incident acute myocardial infarction. Repeat revascularization included any re-operative $C A B G$ or percutaneous coronary intervention $(\mathrm{PCI})$ after operation. Sternal wound infection was defined as an infected wound with coexisting osteomyelitis, dehiscence, or mediastinitis, or that requiring surgical debridement [15].

\section{Statistical analysis}

Continuous variables with normal distribution were presented as means \pm standard deviations. Variables with skewed distribution data were presented as medians (interquartile range). Categorical variables were expressed as frequencies and percentages. Continuous variables were compared using the t-test or Mann-Whitney U-test and categorical variables were compared using the chi-square test or Fisher's exact probability method. A two-tailed $P$ value $<0.05$ was considered statistically significant.

PSM was utilized to adjust for clinical baseline characteristics that were potentially confounding variables. Propensity scores were generated with a multivariable logistic regression analysis model based on all baseline variables listed in Table 1. For patients in the MABG group were matched to the SABG group, using the propensity score with a nearest-neighbor matching algorithm (1:3), and a caliper of 0.02 without replacement. Standardized mean differences (SMD) were determined to compare baseline characteristics of all patients; a SMD $\leq 0.1$ was deemed as an indicator of ideal balance between groups [16]. 
Table 1

Demographic characteristics of MABG versus SABG cohorts post-PSM

\begin{tabular}{|c|c|c|c|c|}
\hline Characteristic & $\begin{array}{l}\text { Overall } \\
(n=919)\end{array}$ & $\begin{array}{l}\text { MABG } \\
(n=243)\end{array}$ & $\begin{array}{l}\text { SABG } \\
(n=676)\end{array}$ & SMD \\
\hline Age (years) & $64.2 \pm 9.0$ & $63.2 \pm 9.1$ & $64.5 \pm 8.9$ & 0.09 \\
\hline $\mathrm{BMI}\left(\mathrm{kg} / \mathrm{m}^{2}\right)$ & $25.5 \pm 3.1$ & $25.7 \pm 2.8$ & $25.4 \pm 3.2$ & 0.1 \\
\hline eGFR $\left(\mathrm{mL} / \mathrm{min} / 1.73 \mathrm{~m}^{2}\right)$ & $92.0 \pm 26.3$ & $93.3 \pm 24.6$ & $91.6 \pm 26.9$ & 0.06 \\
\hline LVEF (\%) & $46.0(42.0,49.0)$ & $46.0(42.0,50.0)$ & $47.0(42.0,49.0)$ & 0.09 \\
\hline LVEF & & & & 0.05 \\
\hline $30 \%-40 \%$ & $179(19.5)$ & $44(18.1)$ & $135(20.0)$ & \\
\hline $41 \%-52 \%$ & $740(80.5)$ & $199(81.9)$ & $541(80.0)$ & \\
\hline LVEDV (mm) & $53.5 \pm 6.9$ & $53.4 \pm 6.7$ & $53.5 \pm 7.1$ & 0.01 \\
\hline Male & $750(81.6)$ & $198(81.5)$ & $552(81.7)$ & 0.01 \\
\hline Smoker & $298(32.4)$ & $76(31.3)$ & $222(32.8)$ & 0.03 \\
\hline DM & & & & 0.02 \\
\hline No history & $610(66.4)$ & $163(67.1)$ & $447(66.1)$ & \\
\hline NIDDM & $226(24.6)$ & $58(23.9)$ & $168(24.9)$ & \\
\hline IDDM & $83(9.0)$ & $22(9.1)$ & $61(9.0)$ & \\
\hline Hypertension & $539(58.7)$ & $140(57.6)$ & $399(59.0)$ & 0.03 \\
\hline Carotid stenosis $>50 \%$ & & & & 0.05 \\
\hline None & $763(83.0)$ & $200(82.3)$ & $563(83.3)$ & \\
\hline Unilateral & $63(6.9)$ & $19(7.8)$ & $44(6.5)$ & \\
\hline Bilateral & $93(10.1)$ & $24(9.9)$ & $69(10.2)$ & \\
\hline COPD & $33(3.6)$ & $9(3.7)$ & $24(3.6)$ & 0.01 \\
\hline
\end{tabular}

The variables are presented as mean \pm standard deviation or median (interquartile range) or number (\%). MABG, multiple arterial bypass graft; SABG, single arterial bypass graft; PSM, propensity score matching; SMD, standardized mean differences; BMI, body mass index; eGFR, estimated glomerular filtration (calculated by modification of diet in renal disease [MDRD]); LVEF, left ventricular ejection fraction; LVEDV, left ventricular end-diastolic volume; DM, diabetes mellitus; NIDDM, non-insulindependent diabetes mellitus; IDDM, insulin-dependent diabetes mellitus; COPD, chronic obstructive pulmonary disease; PVD, peripheral vascular disease; CVA, cerebrovascular accident; $\mathrm{MI}$, myocardial infarction; NYHA, New York Heart Association; PCl, percutaneous coronary intervention; CABG, coronary artery bypass graft. 


\begin{tabular}{|c|c|c|c|c|}
\hline Characteristic & $\begin{array}{l}\text { Overall } \\
(n=919)\end{array}$ & $\begin{array}{l}\text { MABG } \\
(n=243)\end{array}$ & $\begin{array}{l}\text { SABG } \\
(n=676)\end{array}$ & SMD \\
\hline PVD & $58(6.3)$ & $19(7.8)$ & $39(5.8)$ & 0.08 \\
\hline CVA & $63(6.9)$ & $14(5.8)$ & $49(7.2)$ & 0.06 \\
\hline Dialysis & $3(0.3)$ & $1(0.4)$ & $2(0.3)$ & 0.02 \\
\hline Prior MI & $303(33.0)$ & $75(30.9)$ & 288 (33.7) & 0.06 \\
\hline $\mathrm{NYHA} \geq 3$ & $531(57.8)$ & $134(55.1)$ & 397 (58.7) & 0.07 \\
\hline Previous PCl & $93(10.1)$ & $25(10.3)$ & $68(10.1)$ & 0.01 \\
\hline Mitral regurgitation & & & & 0.08 \\
\hline None & $676(73.6)$ & $184(75.7)$ & $492(72.8)$ & \\
\hline Mild & $200(21.8)$ & $50(20.6)$ & $150(22.2)$ & \\
\hline Moderate & $39(4.2)$ & $8(3.3)$ & $31(4.6)$ & \\
\hline Severe & $4(0.4)$ & $1(0.4)$ & $3(0.4)$ & \\
\hline No. vessel disease & & & & 0.04 \\
\hline 2 & 103 (11.2) & $25(10.3)$ & $78(11.5)$ & \\
\hline 3 & $816(88.8)$ & 218 (89.7) & $598(88.5)$ & \\
\hline Left main disease & $269(29.3)$ & $61(25.1)$ & $196(29.0)$ & 0.08 \\
\hline Off-pump CABG & $358(39.0)$ & $88(36.2)$ & 270 (39.9) & 0.08 \\
\hline \multicolumn{5}{|c|}{$\begin{array}{l}\text { The variables are presented as mean } \pm \text { standard deviation or median (interquartile range) or number } \\
\text { (\%). MABG, multiple arterial bypass graft; SABG, single arterial bypass graft; PSM, propensity score } \\
\text { matching; SMD, standardized mean differences; BMI, body mass index; eGFR, estimated glomerular } \\
\text { filtration (calculated by modification of diet in renal disease [MDRD]); LVEF, left ventricular ejection } \\
\text { fraction; LVEDV, left ventricular end-diastolic volume; DM, diabetes mellitus; NIDDM, non-insulin- } \\
\text { dependent diabetes mellitus; IDDM, insulin-dependent diabetes mellitus; COPD, chronic obstructive } \\
\text { pulmonary disease; PVD, peripheral vascular disease; CVA, cerebrovascular accident; MI, myocardial } \\
\text { infarction; NYHA, New York Heart Association; PCI, percutaneous coronary intervention; CABG, } \\
\text { coronary artery bypass graft. }\end{array}$} \\
\hline
\end{tabular}

Time-to-event analyses were performed using Cox proportional hazards models to compare MAEs and death from all causes. The cumulative incidence of death from cardiovascular causes, stroke, $\mathrm{Ml}$, and repeat revascularization were compared using the Fine-Gray models adjusting for death as a competing risk (death from cardiovascular causes were compared after adjusting for death from non-cardiovascular causes as a competing risk). Hazard ratios (HR) and 95\% confidence intervals (Cl) were determined, with assessment of proportional hazard assumption. Cumulative incidence curves were generated for MAEs and death from all causes. Cumulative incidence functions were generated for death from cardiovascular 
causes, stroke, Ml, and repeat revascularization in the Fine-Gray models. All statistical analyses were performed by using the R software (version 3.5.0, http://www.r-project.org/).

\section{Results}

\section{Study population}

Overall, 9812 patients underwent CABG between January 2013 and June 2019. 1641 were eligible for investigation including 247 and 1394 in the MABG and SABG group, respectively (Fig. 1). Prior to matching, patients from the MABG were younger, better renal function, and had a lower proportion of hypertension, diabetes mellitus and previous MI (All P< 0.05) (see Additional file 1). After PSM, 243 patients in the MABG and 676 in the SABG were formed in a 1:3 ratio. All reported parameters were well balanced in both cohorts, with all baseline SMDs $\leq 0.1$ (Table 1). Our data were highly complete with only smoker and cerebrovascular accident of covariates having less than $0.5 \%$ missing data, and the two missing values were imputed to the most common category of binary variables. The median (interquartile range) follow-up time was $3.3(1.8-4.8)$ years and $3.2(1.8-4.6)$ years for MABG and SABG cohorts, respectively. Lost to follow-up occurred in 31 individuals (3.4\%), and no significant difference was found between two cohorts (3.7\% vs. $3.2 \%, P=0.739)$.

\section{In-hospital Outcomes}

The operative and postoperative outcomes for the PSM cohorts are presented in Table 2. In the PSM cohorts, the total number of grafts were equal ( $3.5 \pm 0.9$ vs. $3.4 \pm 0.8, P=0.16)$. Among patients receiving MABG, 193 patients (79.4\%) received RA and 114 (46.9\%) patients received RITA. 64 (26.3\%) patients received more than 2 arterial grafts. In-hospital death (1.6\% vs. $2.2 \%, P=0.783)$ and postoperative complications did not differ between two cohorts (All $P>0.05$ ). We also compared unadjusted in-hospital outcomes between the two groups and except red blood transfusion ( $36.8 \%$ vs. $44.4 \%, P=0.027)$, similar difference was found which corresponded with the results after PSM (see Additional file 2). 
Table 2

Operative and postoperative in-hospital outcomes of the post-PSM MABG versus SABG cohorts

\begin{tabular}{|c|c|c|c|c|}
\hline Outcome & $\begin{array}{l}\text { Overall } \\
(n=919)\end{array}$ & $\begin{array}{l}\text { MABG } \\
(n=243)\end{array}$ & $\begin{array}{l}\text { SABG } \\
(n=676)\end{array}$ & P-value \\
\hline No. of grafts & $3.4 \pm 0.8$ & $3.5 \pm 0.9$ & $3.4 \pm 0.8$ & 0.16 \\
\hline RA & $193(21.0)$ & $193(79.4)$ & - & NA \\
\hline RITA & $114(12.4)$ & $114(46.9)$ & - & NA \\
\hline In-hospital death & $19(2.1)$ & $4(1.6)$ & $15(2.2)$ & 0.783 \\
\hline PMV & $188(20.5)$ & $46(18.9)$ & $142(21.0)$ & 0.491 \\
\hline PICUS & $354(38.5)$ & $86(35.4)$ & $268(39.6)$ & 0.243 \\
\hline IABP & $50(5.4)$ & $11(4.5)$ & $39(5.8)$ & 0.464 \\
\hline Stroke & $6(0.7)$ & $2(0.8)$ & $4(0.6)$ & 0.701 \\
\hline Acute MI & $8(0.9)$ & $2(0.8)$ & $6(0.9)$ & 0.926 \\
\hline Dialysis & $12(1.3)$ & $3(1.2)$ & $9(1.3)$ & 0.909 \\
\hline RBC transfusion & 385 (41.9) & $91(37.4)$ & $294(43.5)$ & 0.102 \\
\hline Sternal wound infection & $8(0.9)$ & $3(1.2)$ & $5(0.7)$ & 0.757 \\
\hline Reoperation for bleeding & $12(1.3)$ & $2(0.8)$ & $10(1.5)$ & 0.657 \\
\hline LVEF (\%) & $47.0(43.0,50.0)$ & $47.0(44.0,51.0)$ & $47.0(42.0,50.0)$ & 0.081 \\
\hline Length of stay (days) & $20.0(16.0,24.0)$ & $20.0(16.0,23.0)$ & $19.0(16.0,24.0)$ & 0.894 \\
\hline \multicolumn{5}{|c|}{$\begin{array}{l}\text { The variables are presented as mean } \pm \text { standard deviation or median (interquartile range) or number } \\
\text { (\%). MABG, multiple arterial bypass graft; SABG, single arterial bypass graft; PSM, propensity score } \\
\text { matching; RA, radial artery; RITA, right internal thoracic artery; PMV, prolonged mechanical ventilation; } \\
\text { PICUS, prolonged intensive care unit stay; IABP, intra-aortic balloon pump; MI, myocardial infarction; } \\
\text { RBC, red blood cell; LVEF, left ventricular ejection fraction (estimated in patients who survival to } \\
\text { discharge); NA, not applicable. }\end{array}$} \\
\hline
\end{tabular}

\section{Death From All Causes And Death From Cardiovascular Causes}

MABG was not associated with a significantly lower probability of death during follow-up period. Death from all causes for MABG was $12.2 \%(95 \% \mathrm{Cl}, 6.3 \%-17.7 \%)$ versus $18.4 \%(95 \% \mathrm{Cl}, 13.3 \%-23.3 \%)$ for SABG $(\mathrm{HR}, 0.77 ; 95 \% \mathrm{Cl}, 0.47-1.24 ; \mathrm{P}=0.29)$ (Table 3 and Fig. $2 \mathrm{~A})$. After adjusting for death from noncardiovascular causes as a competing risk, death from cardiovascular causes for MABG was 9.7\% (95\% 
$\mathrm{Cl}, 5.4 \%-15.6 \%)$ versus $15.5 \%(95 \% \mathrm{Cl}, 11.1 \%-20.6 \%)$ for SABG (HR, $0.73 ; 95 \% \mathrm{Cl}, 0.43-1.25 ; \mathrm{P}=0.26)$ (Table 3 and Fig. 2B).

Table 3

Main outcomes

\begin{tabular}{|c|c|c|c|c|}
\hline Outcome & $\begin{array}{l}\text { MABG } \\
(n=243)\end{array}$ & $\begin{array}{l}\text { SABG } \\
(n=676)\end{array}$ & $\mathrm{HR}(95 \% \mathrm{Cl})$ & $\begin{array}{l}\text { P- } \\
\text { value }\end{array}$ \\
\hline Death from all causes & $12.2(6.3-17.7)$ & $\begin{array}{l}18.4(13.3- \\
23.3)\end{array}$ & $\begin{array}{l}0.77(0.47- \\
1.24)\end{array}$ & 0.29 \\
\hline $\begin{array}{l}\text { Death from cardiovascular } \\
\text { causes }\end{array}$ & $9.7(5.4-15.6)$ & $\begin{array}{l}15.5(11.1- \\
20.6)\end{array}$ & $\begin{array}{l}0.73(0.43- \\
1.25)\end{array}$ & 0.26 \\
\hline $\mathrm{MAEs}^{\dagger}$ & $\begin{array}{l}19.5(12.2- \\
26.1)\end{array}$ & $\begin{array}{l}30.7(24.8- \\
36.1)\end{array}$ & $\begin{array}{l}0.64(0.44- \\
0.94)\end{array}$ & 0.02 \\
\hline Stroke & $4.0(1.6-8.1)$ & $4.7(2.8-7.5)$ & $\begin{array}{l}0.91(0.39- \\
2.16)\end{array}$ & 0.84 \\
\hline MI & $3.2(1.1-6.9)$ & $8.3(5.4-11.8)$ & $\begin{array}{l}0.39(0.16- \\
0.99)\end{array}$ & 0.05 \\
\hline Repeat revascularization & $4.1(1.6-8.5)$ & $10.2(6.9-14.3)$ & $\begin{array}{l}0.42(0.18- \\
0.97)\end{array}$ & 0.03 \\
\hline Sternal wound infection ${ }^{\ddagger}$ & $2.1(0.3-3.9)$ & $1.0(0.3-1.8)$ & $\begin{array}{l}0.50(0.16- \\
1.58)\end{array}$ & 0.24 \\
\hline $\begin{array}{l}{ }^{\dagger} \text { MAEs: major adverse even } \\
\text { revascularization; }{ }^{\ddagger} \text { The even } \\
\text { MABG, multiple arterial byp } \\
\text { hazard ratio; } \mathrm{Cl} \text {, confidence }\end{array}$ & $\begin{array}{l}\mathrm{d} \text { as the compc } \\
\text { to the period } \mathrm{fr} \\
\text {; SABG, single a }\end{array}$ & $\begin{array}{l}\text { of death from } \\
\text { surgical procec } \\
\text { al bypass graf }\end{array}$ & $\begin{array}{l}\text { uses, strok } \\
\text { 6-month o } \\
\text { myocardial }\end{array}$ & $\begin{array}{l}\text { repeat } \\
\text { N-up; } \\
\text { ion; HR, }\end{array}$ \\
\hline
\end{tabular}

\section{Secondary Outcomes}

The MAEs are presented in the Table 3 and Fig. 3A. Fewer patients in the MABG experienced MAEs during the follow-up period. The cumulative incidence of MAEs for MABG was $19.5 \%(95 \% \mathrm{Cl}, 12.2 \%-26.1 \%)$ versus $30.7 \%(95 \% \mathrm{Cl}, 24.8 \%-36.1 \%)$ for SABG (HR, 0.64; 95\% Cl, 0.44-0.94; $\mathrm{P}=0.02)$.

Stroke, Ml, and repeat revascularization were compared in the Fine-Gray models after adjusting for death as a competing risk. MABG was not associated with lower incidence of stroke in comparison with SABG throughout follow-up period (4.0\% vs. 4.7\%; HR, 0.91; 95\% Cl, 0.39-2.16; $\mathrm{P}=0.84$ ) (Table 3 and Fig. 3B). However, the cumulative incidence of MI was significantly lower in the MABG compared with SABG (3.2\% vs. 8.3\%; HR, 0.39; $95 \% \mathrm{Cl}, 0.16-0.99 ; \mathrm{P}=0.05$ ) (Table 3 and Fig. $3 \mathrm{C}$ ). Likewise, the rate of repeat revascularization in the MABG was significantly lower than SABG (4.1\% vs. $10.2 \%$; $\mathrm{HR}, 0.42 ; 95 \% \mathrm{Cl}$, $0.18-0.97 ; P=0.03$ ) (Table 3 and Fig. $3 D$ ). No significant difference was observed between two cohorts 
in sternal wound infection up to 6 months of follow-up after surgery $(\mathrm{HR}, 0.50 ; 95 \% \mathrm{Cl}, 0.16-1.58 ; \mathrm{P}=$ 0.24) (Table 3).

\section{Sensitivity Analysis}

We examined patients who received $\geq 3$ grafts of MABG versus SABG using similar PSM methodology as a sensitivity analysis. 203 patients in the MABG and 566 in the SABG were formed in a 1:3 ratio (data not shown). The rate of MAEs was statistically lower for MABG versus SABG $(17.5 \%$ vs. $28.0 \%$; HR, $0.64 ; 95 \%$ $\mathrm{Cl}, 0.42-0.98 ; \mathrm{P}=0.04)$. Correspondingly, $\mathrm{MABG}$ was associated with lower rate of repeat revascularization compared with SABG (3.5\% vs. 9.6\%; HR, 0.39; $95 \% \mathrm{Cl}, 0.15-0.99 ; \mathrm{P}=0.05)$. However, the incidence of MI was not significantly different in the MABG compared with SABG (2.9\% vs. 8.0\%; HR, $0.41 ; 95 \% \mathrm{Cl}, 0.14-1.16 ; \mathrm{P}=0.08$ ). Death and stroke did not differ between two cohorts (All $\mathrm{P}>0.05$ ) (see Additional file 3).

\section{Discussion}

In this multicenter, population-based PSM study cohort, we evaluated the mid-term outcomes of MABG versus SABG in patients with LVSD, and we found that (1) after PSM, in-hospital outcomes were similar between two cohorts; (2) MABG was associated with lower mid-term risk of MAEs and two individual components: $\mathrm{Ml}$ and repeat revascularization; (3) MABG was not associated with reduced the mid-term rate of death and stroke; and (4) MABG did not increase risk of sternal wound infection. These findings suggested MABG should be importantly taken into consideration in graft selection in patients with mild to moderate LVSD.

The threshold of LVSD defined in the previous guidelines were controversial $[17,18]$, that focused on the argument of a borderline LVEF of 50-55\%. We applied recent update European and American echocardiographic guideline, which defined a LVEF $<53 \%$ as abnormal [19]. In this study, we did not observe worse in-hospital outcomes in the MABG group, as multiple arterial grafting was more complex and time-consuming compared with traditional SVG procedure. The excellent in-hospital outcomes of MABG may probably be related to the improvement in perfusion alteration, myocardial protection, surgical expertise, technique of arterial grafts anastomosis, and perioperative care.

Patients with LVSD differed on pathophysiologic basis from normal LV function, that demonstrated significant abnormalities of ventricular size and function, with shift in the end-systolic pressure-volume relation and decrease in chamber contractility [20]. Based on these changes, LVSD remained associated with diminished long-term survival despite much improvement was achieved in short-term outcomes after CABG [1]. The survival benefit derived from the LITA as a single arterial graft was reported in 1986 by Lytle and colleagues [21], and they also identified LITA as the conduit of choice in patients with low LVEF. The discovery promoted a transition from all SVG-CABG to the current standard of LITA/SVG-CABG. Clinical practice guideline from Society of Thoracic Surgeons (STS) suggested that LITA should be used 
to bypass the LAD (class of recommendation [COR] I, level of evidence [LOE] B) and a second arterial graft (RITA or RA) should be considered in appropriate patients (COR II a, LOE B) [22].

Nevertheless, it remained unclear whether LVSD would negate any potential advantage of MABG, especially in severe cases. In the long-term follow-up studies, Galbut and colleagues [23] reported no multiple arterial survival benefit in PSM bilateral internal thoracic artery CABG (BITA-MABG) versus SABG in patients with LVEF $<30 \%$. Similarly, Mohammadi and colleagues [11] did not find any BITA-MABG benefit in late survival (mean, 8 years) in patients with LVEF $<40 \%$. Schwann and colleagues [10] compared the long-term survival of RA-MABG versus SABG across the entire LV function spectrum, and they found no survival difference in the moderate to severe dysfunction (LVEF $\leq 35 \%$ ) cohorts, but superior survival in the mild dysfunction (LVEF $=36-50 \%$ ) and normal cohorts (LVEF > 50\%) of RA-MABG. In the recent population-based observational study [7], subgroup analysis showed that survival advantage of MABG was achieved in patients with moderate LVSD (LVEF $=35-50 \%$ ), but that disappeared in patients with severe LVSD $($ LVEF $<35 \%)$. These researches potentially raised the question that did it make any sense to perform MABG in the cases of LVEF $<35 \%$ or even $<30 \%$ ? Considering approximately half of venous conduits occluded by $8-10$ years post CABG [24], and to achieve optimal results following $M A B G$, the patients should have a predicted survival of at least 10 years [25]. The vague recommendation that multiple arterial grafts be considered in "appropriate patients" or in patients "with reasonable life expectancy" offers little guidance to surgeons $[22,26]$. In our opinion, the patients with severe LVSD (LVEF < 30\%), with severely impaired of global systolic function and ventricular remodeling, that constitutes a powerful predictor of late mortality, and thus could not be considered as "with reasonable life expectancy".

In our study, we excluded patients with severe LVSD, and a substantial proportion of patients were mild systolic dysfunction (median $46 \%$, interquartile range $42 \%-49 \%$ ) with average age of 64 years old, that may be clinically appropriate candidates for MABG and have a "reasonable life expectancy". However, death from all causes for MABG was $12.2 \%$ and $18.4 \%$ for SABG, with no statistically significant difference detected. The possible explanations for our results may be related to the mid-term follow-up of this study, which was too short to assess for graft mediated difference in survival. Previous studies demonstrated that survival difference may start to appear 5 years after surgery in the general CABG population [9, 27], and patients with LVSD may take longer [28]. Moreover, although we reported a multicenter study cohort, eligible patients for analysis were small sample size, since low proportion of patients were with preoperative LVSD in our databases and multiple arterial conduits were not commonly used in China. It is expected that disparities in graft patency should become manifest in terms of a difference in survival only in the large sample size and long-term following CABG.

In the present study, patients who received either a RITA or RA graft, or both comprised the MABG. The consistent survival benefit of MABG was observed in the previous researches regardless of which second arterial conduit was predominantly used, suggested that both RITA and RA could obtain a similar survival benefit $[9,29,30]$. MABG in this study were performed with several strategies, including single graft anastomosed to a single distal artery, multiple sequential anastomoses, and a composite Y-or T-grafts 
which always use RA as a free graft to achieve total arterial revascularization. Consistent with studies in general CABG population [8, 31], MABG were less likely to undergo acute $\mathrm{MI}$ and repeat revascularization via $\mathrm{PCl}$ or surgical revascularization, and the adverse cardiac events differences appeared earlier than death. There is clear evidence that failure of grafts to $L A D$ adversely affects survival; however, failure of grafts to other target vessels is more likely to result in non-fatal cardiac events [32]. Despite BITA was identified as an independent risk factor for sternal wound infection [33], we did not observe a higher incidence of sternal wound infection in MABG up to 6 months of follow-up after surgery. This discrepancy may be explained by our and other centers' technique of skeletonizing the ITA, which preserves the lymphatic vessels and more of the blood supply to the sternum, compared with the more commonly used technique of ITA harvesting with a wide pedicle.

We performed patients who received $\geq 3$ grafts $C A B G$ as a sensitivity analysis, and the results were generally corresponded with our primary analysis. In our sensitivity analysis, there appeared to be more benefit in the SABG with increasing use of SVG, as reduction of disparities showed between two cohorts. Furthermore, there trended to decreased cardiovascular events in the MABG, with the ratio of SVG increased. These findings were consistent with the subgroup analysis in general CABG population study by Rocha and colleagues [34]. Whereas, further investigations were needed, as potential type II error associated with a small sample size may occur when creating subgroups in a sensitivity analysis.

\section{Study Limitations}

Our study had several limitations. First, this was a retrospective study; therefore, potential biases could not be fully avoided, and a multicenter randomized controlled study with larger sample size and longer follow-up would add more weight to these results. Second, selection bias of patients could not be fully avoided. Although we had excluded patients with severe LVSD (LVEF $<30 \%)$ and urgent states such as emergency surgery or preoperative hemodynamic instability, arterial conduits used were at the discretion of surgeons. Surgeons would typically perform multiple arterial grafts if patients are expected to enjoy long survival after CABG, and PSM cannot adjust for this. Moreover, Surgeons expertise was also not taken into our consideration since that might affect the efficiency of treatment. Third, we were limited to obtain complete data of the CT angiography or coronary angiography; thus, it was unclear that adverse cardiac events (MI and repeat revascularization) occurred in grafts, treated target vessels or other native vessels of new-onset.

\section{Conclusion}

In this multicenter population-based, PSM study evaluating the mid-term outcomes of MABG versus $S A B G$, we found that MABG was associated with reduced the rate of MAEs, MI, and repeat revascularization, but not with reduced the rate of death and stroke. MABG did not increase incidence of sternal wound infection or in-hospital mortality. Additional adequately powered studies are required to further evaluate the long-term outcomes of MABG in patients with LVSD. 


\section{Abbreviations}

CABG

Coronary artery bypass graft; LVSD:Left ventricular systolic dysfunction; LVEF:Left ventricular ejection fraction; MABG:Multiple arterial bypass graft; SABG:Single arterial bypass graft; LITA:Left internal thoracic artery; MAEs:Major adverse events; PSM:Propensity score matching; eGFR, Estimated glomerular filtration; DM:Diabetes mellitus; MI:Myocardial infarction; NYHA:New York Heart Association; PCI:Percutaneous coronary intervention; RA:Radial artery; RITA:Right internal thoracic artery; BITA:Bilateral internal thoracic artery; HR:Hazard ratio; Cl:Confidence interval

\section{Declarations}

\section{Ethics approval and consent to participate}

The Institutional Review Board reviewed and approved the study. Consent to participate for this study was waived because no individual patients were identified.

\section{Consent for publication}

Not applicable.

\section{Availability of data and materials}

All data have been retrieved from the databases and are available from the corresponding author on reasonable request.

\section{Competing interests}

The authors declare that they have no competing interests.

\section{Funding}

This work was supported by the National Natural Science Foundation of China (No. 81700415) and The Project of Invigorating Health Care through Science, Technology and Education: Jiangsu Provincial Key Medical Discipline (Laboratory) (ZDXKA2016021).

\section{Authors' contributions}

We confirm that the manuscript has been read and approved by all named authors. We further confirm that the order of authors listed in the manuscript has been approved by all of us. HZ, RW participated in conception and design of the study. HZ, WC, YZ, LG, MY obtained, organized and cleaned the dataset. HZ, $\mathrm{RW}, \mathrm{XC}$ performed data analyses. $\mathrm{HZ}, \mathrm{RW}$ drafted the article.

\section{Acknowledgements}


We want to thank the statistician of statistical guidance of this work: Haozhe Zhang, PhD, worked in Al Platform, Microsoft Corporation.

\section{Author details}

${ }^{1}$ Department of Thoracic and Cardiovascular Surgery, Nanjing First Hospital, Nanjing Medical University, No. 68 Changle Road, Nanjing 210006, China. ${ }^{2}$ Department of Epidemiology and Biostatistics, School of Public Health, Nanjing Medical University, No. 101 Longmian avenue, Nanjing 211166, China.

${ }^{3}$ Department of Cardio-thoracic Surgery, Shanghai Eighth People's Hospital, No. 8 Caobao Road, Shanghai 200235, China. ${ }^{4}$ Department of Cardiovascular Surgery, Shanghai General Hospital, Shanghai Jiao Tong University School of Medicine, No. 100 Haining Road, Shanghai 200080, China.

\section{References}

1. Shahian DM, O'Brien SM, Filardo G, Ferraris VA, Haan CK, Rich JB, et al. The Society of Thoracic Surgeons 2008 cardiac surgery risk models: part 1-coronary artery bypass grafting surgery. Ann Thorac Surg. 2009;88:Suppl 2-22.

2. Bangalore S, Guo Y, Samadashvili Z, Blecker S, Hannan EL. Revascularization in Patients With Multivessel Coronary Artery Disease and Severe Left Ventricular Systolic Dysfunction: EverolimusEluting Stents Versus Coronary Artery Bypass Graft Surgery. Circulation. 2016;133:2132-40.

3. Velazquez EJ, Lee KL, Jones RH, Al-Khalidi HR, Hill JA, Panza JA, et al. Coronary-Artery Bypass Surgery in Patients with Ischemic Cardiomyopathy. N Engl J Med. 2016;374:1511-20.

4. Velazquez EJ, Williams JB, Yow E, Shaw LK, Lee KL, Phillips HR, et al. Long-term survival of patients with ischemic cardiomyopathy treated by coronary artery bypass grafting versus medical therapy. Ann Thorac Surg. 2012;93:523-30.

5. Yüksel V, Canbaz S, Ege T. Coronary artery bypass graft surgery in patients with left ventricular dysfunction. J Cardiovasc Surg (Torino). 2015;56:655-9.

6. Bonow RO, Maurer G, Lee KL, Holly TA, Binkley PF, Desvigne-Nickens P, et al. Myocardial viability and survival in ischemic left ventricular dysfunction. N Engl J Med. 2011;364:1617-25.

7. Pu A, Ding L, Shin J, Price J, Skarsgard P, Wong DR, et al. Long-term Outcomes of Multiple Arterial Coronary Artery Bypass Grafting: A Population-Based Study of Patients in British Columbia, Canada. JAMA Cardiol. 2017;2:1187-96.

8. Chikwe J, Sun E, Hannan EL, Itagaki S, Lee T, Adams DH, et al. Outcomes of Second Arterial Conduits in Patients Undergoing Multivessel Coronary Artery Bypass Graft Surgery. J Am Coll Cardiol. 2019;74:2238-48.

9. Goldstone AB, Chiu P, Baiocchi M, Wang H, Lingala B, Boyd JH, et al. Second Arterial Versus Venous Conduits for Multivessel Coronary Artery Bypass Surgery in California. Circulation. 2018;137:1698707. 
10. Schwann TA, Al-Shaar L, Tranbaugh RF, Dimitrova KR, Hoffman DM, Geller CM, et al. Multi Versus Single Arterial Coronary Bypass Graft Surgery Across the Ejection Fraction Spectrum. Ann Thorac Surg. 2015;100:810-17.

11. Mohammadi S, Kalavrouziotis D, Cresce G, Dagenais F, Dumont E, Charbonneau E, et al. Bilateral internal thoracic artery use in patients with low ejection fraction: is there any additional long-term benefit? Eur J Cardiothorac Surg. 2014;46:425-31.

12. Locker C, Schaff HV, Dearani JA, Joyce LD, Park SJ, Burkhart HM, et al. Multiple arterial grafts improve late survival of patients undergoing coronary artery bypass graft surgery: analysis of 8622 patients with multivessel disease. Circulation. 2012;126:1023-30.

13. O'Brien SM, Feng L, He X, Xian Y, Jacobs JP, Badhwar V, et al. The Society of Thoracic Surgeons 2018 Adult Cardiac Surgery Risk Models: Part 2-Statistical Methods and Results. Ann Thorac Surg. 2018;105:1419-28.

14. Ettema RG, Peelen LM, Schuurmans MJ, Nierich AP, Kalkman CJ, Moons KG. Prediction models for prolonged intensive care unit stay after cardiac surgery: systematic review and validation study. Circulation. 2010;122:682-9.

15. Southern DA, Doherty C, De Souza MA, Quan H, Harrop AR, Nickerson D, et al. Charts versus Discharge ICD-10 Coding for Sternal Wound Infection Following Coronary Artery Bypass Grafting. Perspect Health Inf Manag. 2015;12:1e.

16. Silber JH, Rosenbaum PR, Trudeau ME, Even-Shoshan O, Chen W, Zhang X, et al. Multivariate matching and bias reduction in the surgical outcomes study. Med Care. 2001;39:1048-64.

17. Lang RM, Bierig M, Devereux RB, Flachskampf FA, Foster E, Pellikka PA, et al. Recommendations for chamber quantification: a report from the American Society of Echocardiography's Guidelines and Standards Committee and the Chamber Quantification Writing Group, developed in conjunction with the European Association of Echocardiography, a branch of the European Society of Cardiology. J Am Soc Echocardiogr. 2005;18:1440-63.

18. McMurray JJ, Adamopoulos S, Anker SD, Auricchio A, Böhm M, Dickstein K, et al. ESC Guidelines for the diagnosis and treatment of acute and chronic heart failure 2012: The Task Force for the Diagnosis and Treatment of Acute and Chronic Heart Failure 2012 of the European Society of Cardiology. Developed in collaboration with the Heart Failure Association (HFA) of the ESC. Eur Heart J. 2012;33:1787-847.

19. Lang RM, Badano LP, Mor-Avi V, Afilalo J, Armstrong A, Ernande L, et al. Recommendations for cardiac chamber quantification by echocardiography in adults: an update from the American Society of Echocardiography and the European Association of Cardiovascular Imaging. Eur Heart $\mathrm{J}$ Cardiovasc Imaging. 2015;16:233-70.

20. He KL, Burkhoff D, Leng WX, Liang ZR, Fan L, Wang J, et al. Comparison of ventricular structure and function in Chinese patients with heart failure and ejection fractions $>55 \%$ versus $40-55 \%$ versus < 40\%. Am J Cardiol. 2009;103:845-51. 
21. Loop FD, Lytle BW, Cosgrove DM, Stewart RW, Goormastic M, Williams GW, et al. Influence of the internal-mammary-artery graft on 10-year survival and other cardiac events. N Engl J Med. 1986;314:1-6.

22. Aldea GS, Bakaeen FG, Pal J, Fremes S, Head SJ, Sabik J, et al. The Society of Thoracic Surgeons Clinical Practice Guidelines on Arterial Conduits for Coronary Arter y Bypass Grafting. Ann Thorac Surg. 2016;101:801-9.

23. Galbut DL, Kurlansky PA, Traad EA, Dorman MJ, Zucker M, Ebra G. Bilateral internal thoracic artery grafting improves long-term survival in patients with reduced ejection fraction: a propensity-matched study with 30-year follow-up. J Thorac Cardiovasc Surg. 2012;143:844-53.

24. Goldman S, Zadina K, Moritz T, Ovitt T, Sethi G, Copeland JG, et al. Long-term patency of saphenous vein and left internal mammary artery grafts after coronary artery bypass surgery: results from a Department of Veterans Affairs Cooperative Study. J Am Coll Cardiol. 2004;44:2149-56.

25. Lytle BW. Bilateral internal thoracic artery grafting. Ann Cardiothorac Surg. 2013;2:485-92.

26. Authors/Task Force m. Windecker S, Kolh P, Alfonso F, Collet JP, Cremer J, et al. 2014 ESC/EACTS Guidelines on myocardial revascularization: The Task Force on Myocardial Revascularization of the European Society of Cardiology (ESC) and the European Association for Cardio-Thoracic Surgery (EACTS)Developed with the special contribution of the European Association of Percutaneous Cardiovascular Interventions (EAPCI). Eur Heart J. 2014; 35: 2541-619.

27. Parasca CA, Head SJ, Mohr FW, Mack MJ, Morice MC, Holmes DR, et al. The impact of a second arterial graft on 5-year outcomes after coronary artery bypass grafting in the Synergy Between Percutaneous Coronary Intervention With TAXUS and Cardiac Surgery Trial and Registry. J Thorac Cardiovasc Surg. 2015;150:597-606.

28. Lytle BW, Blackstone EH, Sabik JF, Houghtaling P, Loop FD, Cosgrove DM. The effect of bilateral internal thoracic artery grafting on survival during 20 postoperative years. Ann Thorac Surg. 2004;78:2005-12.

29. Tranbaugh RF, Schwann TA, Swistel DG, Dimitrova KR, Al-Shaar L, Hoffman DM, et al. Coronary Artery Bypass Graft Surgery Using the Radial Artery, Right Internal Thoracic Artery, or Saphenous Vein as the Second Conduit. Ann Thorac Surg. 2017;104:553-9.

30. Taggart DP, Altman DG, Flather M, Gerry S, Gray A, Lees B, et al. Associations Between Adding a Radial Artery Graft to Single and Bilateral Internal Thoracic Artery Grafts and Outcomes: Insights From the Arterial Revascularization Trial. Circulation. 2017;136:454-63.

31. Gaudino M, Benedetto U, Fremes S, Biondi-Zoccai G, Sedrakyan A, Puskas JD, et al. Radial-Artery or Saphenous-Vein Grafts in Coronary-Artery Bypass Surgery. N Engl J Med. 2018;378:2069-77.

32. Shavadia J, Norris CM, Graham MM, Verma S, Ali I, Bainey KR. Symptomatic graft failure and impact on clinical outcome after coronary artery bypass grafting surgery: Results from the Alberta Provincial Project for Outcome Assessment in Coronary Heart Disease registry. Am Heart J. 2015;169:833-40.

33. Taggart DP, Altman DG, Gray AM, Lees B, Nugara F, Yu LM, et al. Randomized trial to compare bilateral vs. single internal mammary coronary artery bypass grafting: 1-year results of the Arterial 
Revascularisation Trial (ART). Eur Heart J. 2010;31:2470-81.

34. Rocha RV, Tam DY, Karkhanis R, Wang X, Austin PC, Ko DT, et al. Long-term Outcomes Associated With Total Arterial Revascularization vs Non-Total Arterial Revascularization. JAMA Cardiol. 2020. doi:10.1001/jamacardio.2019.6104.

\section{Figures}

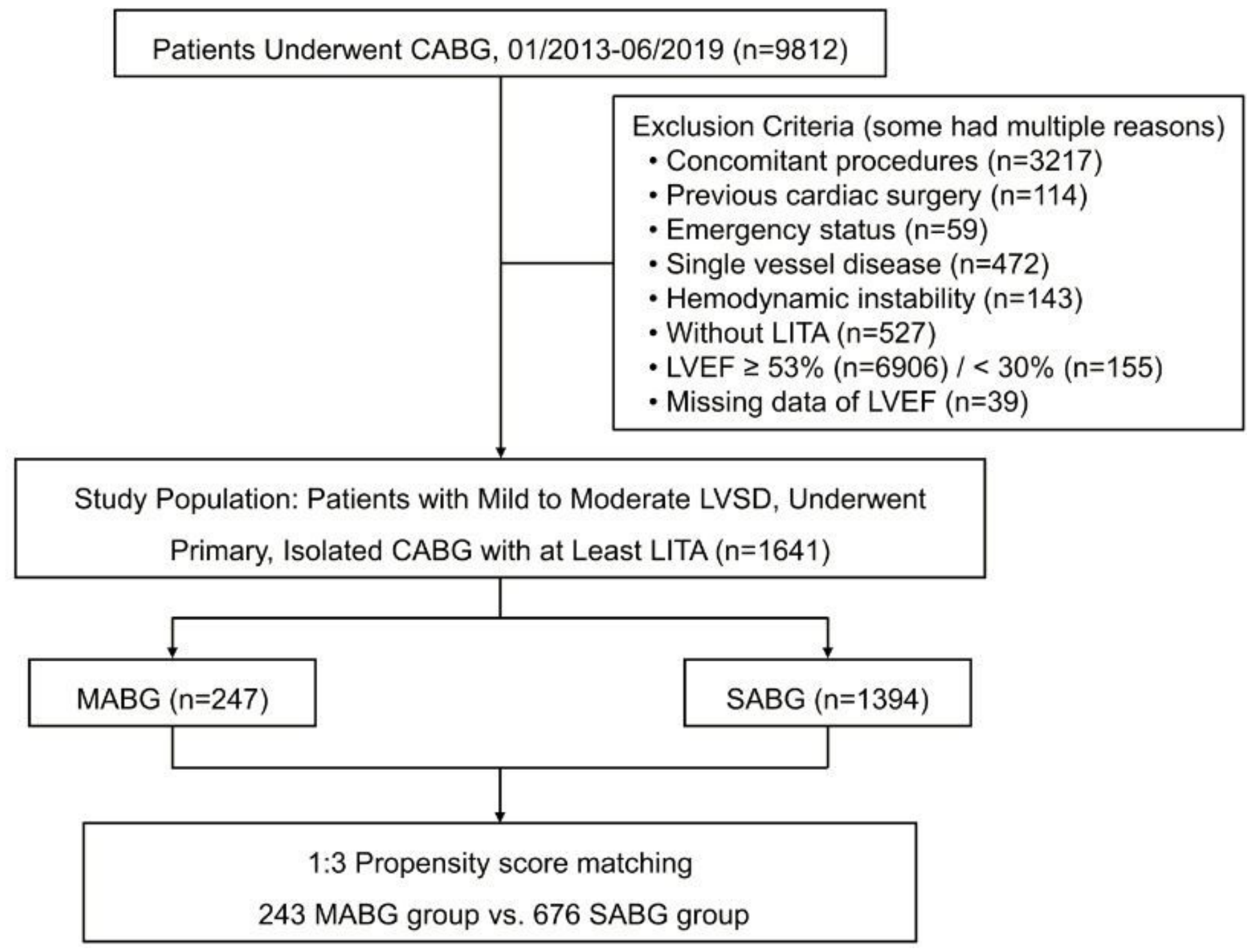

Figure 1

Flowchart showing patients included in the analysis. CABG, coronary artery bypass grafting; LITA, left internal thoracic artery; LVEF, Left ventricular ejection fraction; MABG, multiple arterial bypass graft; SABG, single arterial bypass graft. 

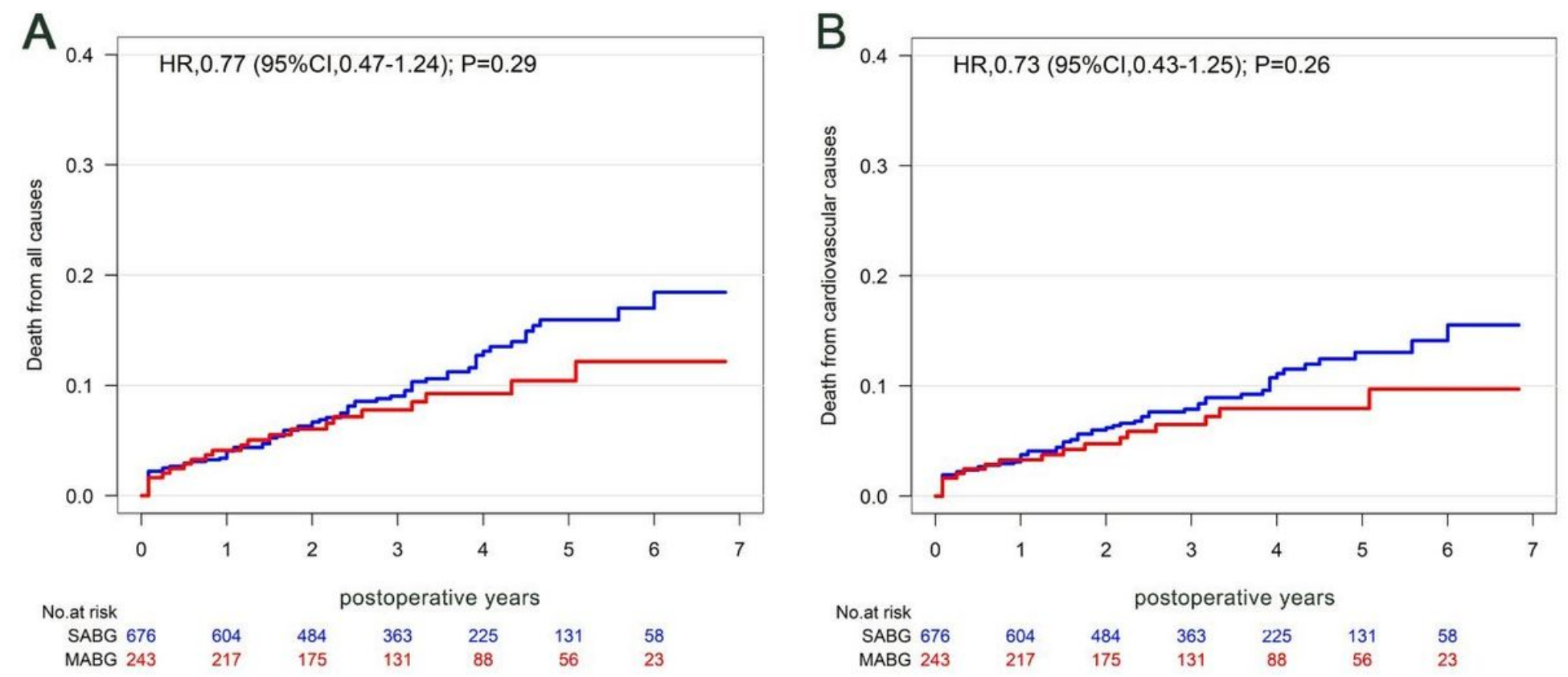

\section{Figure 2}

Cumulative incidence curves for the rate of death from all causes $(A)$ and death from cardiovascular causes (B). HR, hazard ratio; $\mathrm{Cl}$, confidence interval; $M A B G$, multiple arterial bypass graft; $S A B G$, single arterial bypass graft. 
A

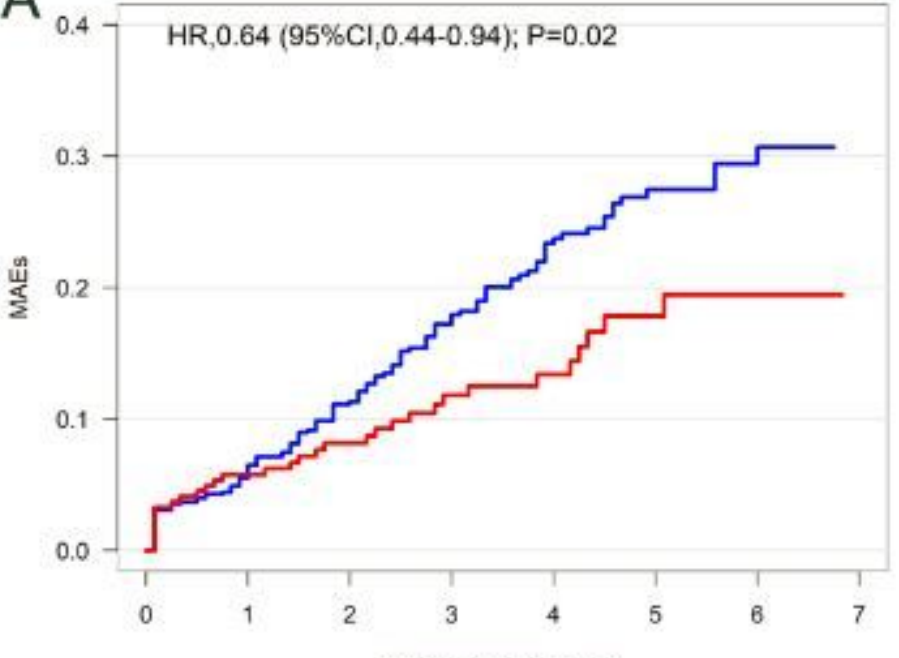

No.at risk

SABG 676

MABG 243

postoperative years

$127-55-23$

C

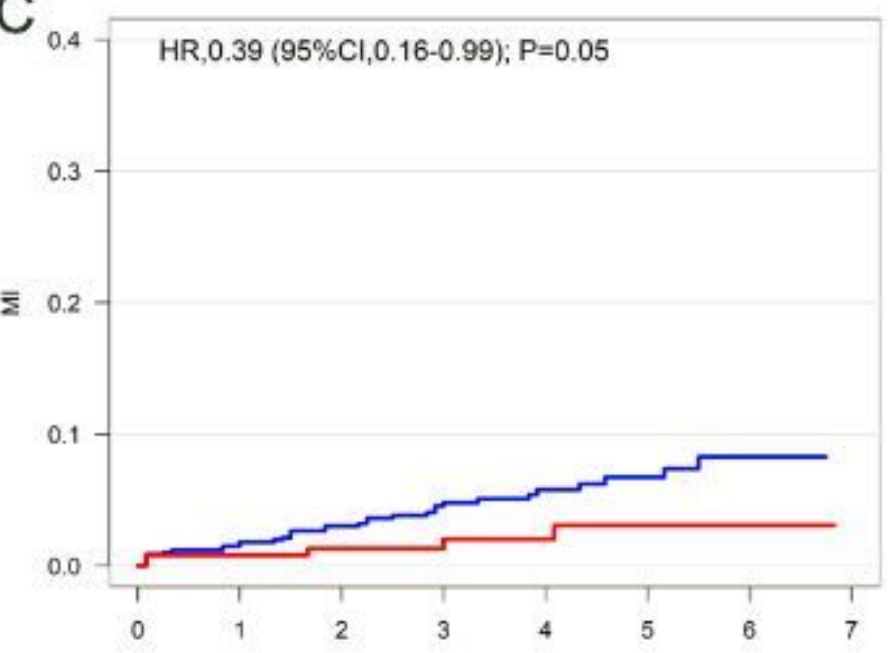

No.at risk

SABG 678

MABG 243

\begin{tabular}{lrrrrr}
\multicolumn{7}{c}{ postoperative years } \\
598 & 474 & 354 & 220 & 128 & 56 \\
215 & 174 & 131 & 80 & 56 & 23
\end{tabular}

B

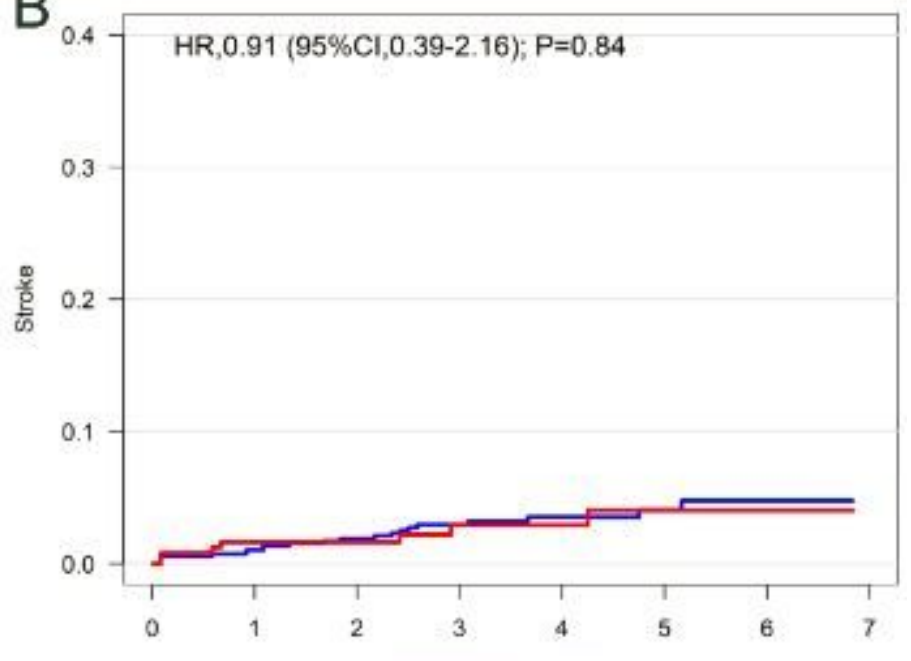

No.et risk postoperative years

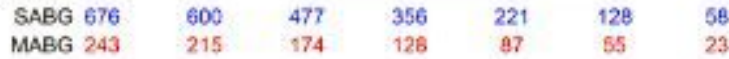

D

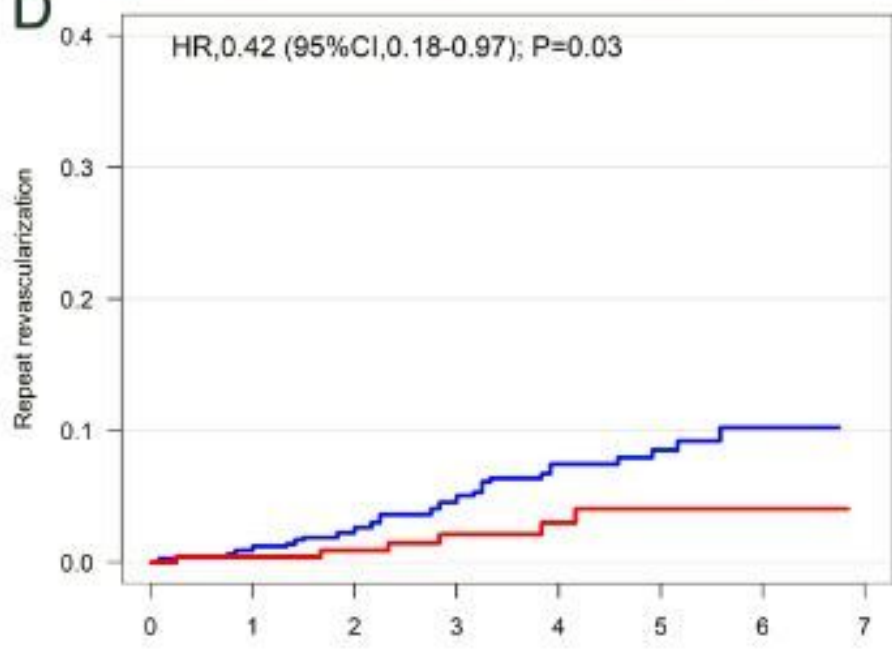

No.at risk postoperative years

$\begin{array}{ccccccc}\text { SAEG } 676 & 600 & 474 & 349 & 214 & 123 & 55 \\ \text { MAEG 243 } & 216 & 175 & 130 & 88 & 56 & 23\end{array}$

\section{Figure 3}

Cumulative incidence curves for the rate of MAEs (A), stroke (B), MI (C), and repeat revascularization (D). $\mathrm{HR}$, hazard ratio; $\mathrm{Cl}$, confidence interval; MAEs, major adverse events; $\mathrm{MABG}$, multiple arterial bypass graft; $S A B G$, single arterial bypass graft.

\section{Supplementary Files}

This is a list of supplementary files associated with this preprint. Click to download.

- Additionalfiles.docx 